\title{
BMJ Open Impact of informational and relational continuity for people with palliative care needs: a mixed methods rapid review
}

Briony F Hudson, ${ }^{\oplus 1,2}$ Sabine Best, ${ }^{1}$ Patrick Stone, ${ }^{2}$ Thomas (Bill) Noble ${ }^{3}$

To cite: Hudson BF, Best $\mathrm{S}$, Stone $\mathrm{P}$, et al. Impact of informational and relational continuity for people with palliative care needs: a mixed methods rapid review. BMJ Open 2019;9:e027323. doi:10.1136/ bmjopen-2018-027323

- Prepublication history and additional material for this paper are available online. To view these files, please visit the journal online (http://dx.doi org/10.1136/bmjopen-2018027323).

Received 18 0ctober 2018 Revised 8 April 2019 Accepted 17 April 2019
A) Check for updates

(c) Author(s) (or their employer(s)) 2019. Re-use permitted under CC BY-NC. No commercial re-use. See rights and permissions. Published by BMJ.

${ }^{1}$ Marie Curie, London, UK ${ }^{2}$ Marie Curie Palliative Care Research Department, Division of Psychiatry, University College London, London, UK

${ }^{3}$ Academic Unit of Supportive Care, University of Sheffield, Sheffield, UK

Correspondence to Dr Briony F Hudson; b.hudson@ucl.ac.uk

\section{ABSTRACT}

Objective To identify and synthesise existing literature exploring the impact of relational and informational continuity of care on preferred place of death, hospital admissions and satisfaction for palliative care patients in qualitative, quantitative and mixed methods literature.

Design A mixed methods rapid review.

Methods PUBMED, PsychINFO, CINAHL were searched from June 2008 to June 2018 in order to identify original peer reviewed, primary qualitative, quantitative or mixed methods research exploring the impact of continuity of care for people receiving palliative care. Synthesis methods as outlined by the Cochrane Qualitative and Implementation Methods Group were applied to qualitative studies while meta-analyses for quantitative data were planned.

Outcomes The impact of interventions designed to promote continuity of care for people receiving palliative care on the following outcomes was explored: achieving preferred place of death, satisfaction with care and avoidable hospital admissions.

Results 18 eligible papers were identified (11 qualitative, 6 quantitative and 1 mixed methods papers). In all, 1951 patients and 190 family caregivers were recruited across included studies. Meta-analyses were not possible due to heterogeneity in outcome measures and tools used. Two studies described positive impact on facilitating preferred place of death. Four described a reduction in avoidable hospital admissions. No negative impacts of interventions designed to promote continuity were reported. Patient satisfaction was not assessed in quantitative studies. Participants described a significant impact on their experiences as a result of the lack of informational and relational continuity.

Conclusions This rapid review highlights the impact that continuity of care can have on the experiences of patients receiving palliative care. The evidence for the impact of continuity on place of death and hospital admissions is limited. Methods for enhancing, and recording continuity should be considered in the design and development of future healthcare interventions to support people receiving palliative care.

\section{INTRODUCTION}

Continuity of care is an important aspect of healthcare, but is often lacking. Continuity of

\section{Strengths and limitations of this study}

- This is the first mixed methods rapid review to explore the impact of continuity of care for palliative care patients.

- The inclusion of both qualitative and quantitative data provides rich insights into the experiences of patients and families, although the views of healthcare providers were not included.

- Only studies written in English and published within the last 10 years were included, which may introduce a risk of bias.

- Half of included studies were conducted in the UK yet experiences associated with both good and poor continuity may transcend national borders.

care can take a range of forms, from continuous relationships with clinicians (relational continuity) to coordinated, comprehensive information sharing (informational continuity) and shared management plans (management continuity) within a range of services or professionals. $^{12}$

In a review of continuity across multidisciplinary contexts, Haggerty et al argue that continuity is experienced by patients as the "perception that providers know what has happened before, that different providers agree on a management plan, and that a provider who knows them will care for them in the future.'

The generation of accumulated knowledge and trust between a health professional and patient achieved through relational continuity $^{3}$ is valued by both patients ${ }^{4}$ and clinicians. ${ }^{5}$ High levels of management and informational continuity contribute to effective and efficient care. On the other hand, the same long term relationships between healthcare providers and patients may also open the door to collusion ${ }^{6}$ or prevent patients benefiting from the opinions of a fresh pair of eyes. ${ }^{7}$ 
On balance, evidence suggests continuity is beneficial for a range of populations across a range of outcomes. Lower levels of continuity have been associated with higher emergency department use throughout the life span. ${ }^{89}$ Continuity has also been associated with patient satisfaction, ${ }^{10}$ fewer hospital admissions ${ }^{11}{ }^{12}$ and improved care for long term conditions such as diabetes. ${ }^{13}$ Compelling evidence for the promotion of relational continuity was provided in a recent systematic review which highlighted a relationship between increased continuity and lower mortality rates. ${ }^{14}$ In response, international policies and charters call for the promotion of continuity within healthcare services. ${ }^{15-17}$

However, the challenges to ensuring continuity are many and multifaceted. Within healthcare services that face growing demands and reducing resources, promoting and achieving continuity of care can be difficult. ${ }^{18}$ The size of medical organisations is growing ${ }^{19}$ and the number of physicians seeing patients on a part time basis is increasing. ${ }^{20}$ The demands for rapid access to care are hard to balance with the demands for continuity.

Continuity may become increasingly important or valued in a person's care as they age, develop comorbid conditions or as their health deteriorates. ${ }^{121}$ It has been estimated that $69 \%-82 \%$ of persons who die in high-income countries would benefit from palliative care, ${ }^{22}$ a figure which is likely to increase. As the population of many western countries continues to age, the need for greater continuity in services may become more pressing as the impact of the presence or absence of continuity may be more keenly felt towards the end of life.

The number of different professionals and services involved in community palliative care can make continuity of care challenging, ${ }^{23}$ yet continuity was identified as one of the top 10 issues identified by the James Lind Alliance Palliative and end of life care Priority Setting Partnership. ${ }^{24}$

The literature exploring the impact of continuity in palliative care is relatively young, yet promising. Continuity has been reported to be independently associated with patient ratings of care during cancer treatment, ${ }^{25}$ while greater involvement of primary care physicians at the end of life is associated with deaths outside of hospital, and receiving home care or hospice support ${ }^{26}$ A review of integrated palliative care models across Europe called for greater efforts to enhance continuity. ${ }^{27}$

In response, this rapid review aims to identify and synthesise the existing literature, exploring the impact of continuity of care (both relational and informational) on the experiences of palliative care patients and their families.

\section{OBJECTIVES}

1. To identify, from the perspectives of people receiving palliative care and their families, friends or carers the potential impact of continuity (or lack of continuity) on their experiences of care.
2. To explore the impact of interventions designed to promote continuity for people receiving palliative care on achieving preferred place of death, reducing avoidable hospital admissions and satisfaction with care.

\section{METHODS}

The guidelines put forward by the Palliative Care Evidence Review Service $\left(\mathrm{PaCERS}^{28}\right.$ ) were used to shape this rapid review.

\section{Inclusion criteria for studies}

Types of participants

Interventions recruiting adults (aged over 18 years) receiving palliative care and/or their family, friends or carers. Participants at all stages of a terminal illness, including the dying phase were included, in line with previous systematic reviews in this area. ${ }^{29}$

\section{Types of studies and outcomes}

Original peer reviewed studies published in English within the last 10 years (June 2008-June 2018) presenting primary qualitative, quantitative or mixed methods interventions exploring the impact of continuity in palliative care were eligible for inclusion.

Specifically:

- Qualitative studies collecting information about the experience of continuity for palliative care patients or their families (including bereaved family members). Studies also including the views of healthcare providers were included if the voices of patients and carers could be separated.

- Prospective interventions designed to promote continuity and explore the impact of this on reducing avoidable hospital admissions, enabling preference for place of death, or patient or carer satisfaction with care. The following methodologies were included randomised controlled trials, non-randomised controlled trials/quasiexperimental trials and beforeafter studies.

Retrospective studies, grey literature, reviews, conference abstracts and qualitative studies exploring the perspectives of healthcare professionals were not eligible.

\begin{tabular}{|c|c|}
\hline Palliative care & $\begin{array}{l}\text { ((terminal }{ }^{\star} \text { OR (advanced disease) OR } \\
\text { palliativ }{ }^{\star} \text { OR (palliative care) OR (palliative } \\
\text { medicine) OR (end of life)) }\end{array}$ \\
\hline $\begin{array}{l}\text { AND } \\
\text { Continuity }\end{array}$ & $\begin{array}{l}\text { ((continuity) OR (partnership working) } \\
\text { OR (collaborat*) OR (communication) OR } \\
\text { (shared working) OR (joint working) OR } \\
\text { (shared care) OR (extended team)) }\end{array}$ \\
\hline AND outcomes & $\begin{array}{l}\text { ((experience) OR (satisfaction) OR (place } \\
\text { of death) OR (health care utilisation) } \\
\left.\text { OR (appointment }{ }^{\star}\right) \text { OR (admission*) OR } \\
\text { (hospital admission) OR (readmission) OR } \\
\text { (emergency)) }\end{array}$ \\
\hline
\end{tabular}




\begin{tabular}{|c|c|c|}
\hline All studies & Intervention studies & Qualitative studies \\
\hline 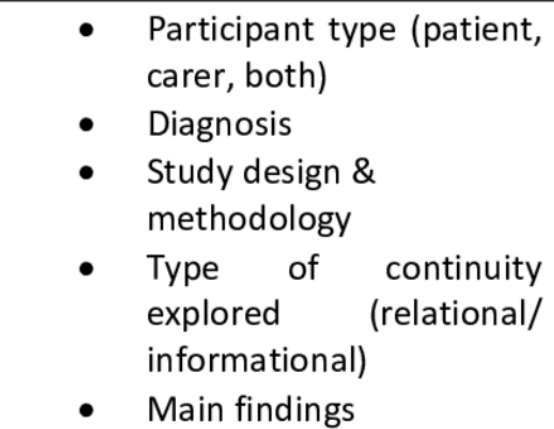 & $\begin{array}{l}\text { - Components of } \\
\text { interventions } \\
\text { - Impact of intervention } \\
\text { on specified outcomes } \\
\text { (patient/carer } \\
\text { satisfaction with care, } \\
\text { preferred place of death } \\
\text { or reducing hospital } \\
\text { admissions) }\end{array}$ & $\begin{array}{l}\text { - All text labeled as } \\
\text { "results" or "findings" } \\
\text { (both in the abstracts } \\
\text { and texts of papers) were } \\
\text { extracted. }\end{array}$ \\
\hline
\end{tabular}

Figure 1 Data extracted from identified studies.

\section{Search method for identification of studies}

\section{Electronic searches}

The following databases were searched: PUBMED, PsychINFO, CINAHL. Reference lists and forward searches of relevant publications were also screened.

\section{Search terms}

Based on previous reviews of the literature on palliative care and continuity, ${ }^{23}{ }^{30}$ the free text and indexed terms listed in table 1 were used to identify relevant articles.

\section{Data collection and analysis}

\section{Data screening}

Studies were screened by one researcher $(\mathrm{BFH})$ and eligible studies were checked by a second (BN). Queries over the eligibility of studies were discussed with the research team ( $\mathrm{SB}, \mathrm{BN}$ and $\mathrm{BFH})$.

\section{Data extraction}

A unique form was developed to capture the following data from each eligible study. Figure 1 outlines the data that were extracted from each study.

\section{Data analysis}

Quality assessment

To assess the methodological rigour of included studies, a tool developed by Hawker $e t a l^{\beta 1}$ was used. The results are presented in online appendix 1.

\section{Quantitative data analysis}

Due to the heterogeneity of outcomes, meta-analyses were not possible. A narrative summary of studies was provided.

\section{Qualitative data analysis}

Synthesis methods as outlined by the Cochrane Qualitative and Implementation Methods Group were applied and the review was reported according to Enhancing transparency in reporting the synthesis of qualitative research guidelines. ${ }^{32}$ Qualitative synthesis involves reinterpretation by considering the findings of multiple studies within an analysis, ${ }^{33}$ using a three-step process: coding, developing descriptive themes and generating analytical themes. ${ }^{34}$ All data titled findings or results were entered into NVivo for analysis, in line with previous reviews using qualitative synthesis. ${ }^{345}$

\section{Patient and public involvement}

This review was motivated by the priorities identified in the James Lind Alliance Palliative and end of life care Priority Setting Partnership, ${ }^{24}$ which included the views of patients and the public. No further patient and public involvement was incorporated into this review.

\section{RESULTS}

Figure 2 presents a flow diagram of the study selection process. The initial search yielded 339 citations and 18 articles met the inclusion criteria (11 qualitative, 6 quantitative and 1 mixed methods).

\section{Study characteristics}

Half of included studies were conducted in the UK (50\%, $\mathrm{n}=9$ ), three were conducted in the USA or Canada, two in Australia and one each in Iceland, the Netherlands, Sweden and Denmark. Tables 2 and 3 outline the sample, methodology, components of intervention, types of continuity assessed, outcome measures included and whether the intervention was found to be effective.

\section{Study methodology}

The majority of eligible quantitative and mixed methods studies used quasiexperimental methodologies (86\%, $\mathrm{n}=6$ ). One randomised controlled trial ${ }^{36}$ was included. Two interventional studies included a control group, ${ }^{36} 37$ two used an interrupted time series design ${ }^{38} 39$ and three did not include a comparison group. ${ }^{40-42}$

For qualitative studies, semi structured interviews with patients or their carers were the most common method of data collection ${ }^{43-49}(64 \%$ of qualitative studies, $\mathrm{n}=7$ ), three studies undertook multiple interviews with participants, ${ }^{50-52}$ while one utilised focus groups. ${ }^{53}$ Qualitative data were analysed using thematic 


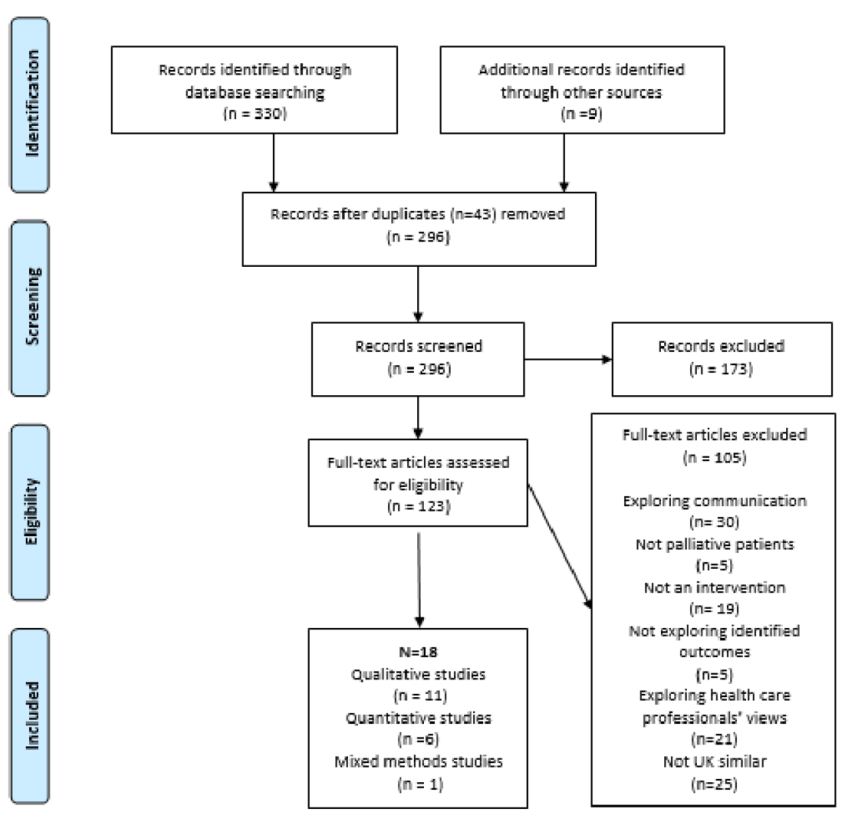

Figure 2 Preferred Reporting Items for Systematic Reviews and Meta-Analyses flow diagram outlining study identification, screening, eligibility and inclusion.

analysis, ${ }^{44-46} 4951$ framework analysis, ${ }^{47} 48$ a qualitative descriptive approach ${ }^{50}$ or content analysis. ${ }^{43}$

\section{Participants}

In all, 1951 patients and 190 family caregivers were recruited across included studies. Most studies $(n=10)$ recruited patients with a range of illnesses, identified as requiring palliative care, three studies recruited patients with cancer ${ }^{36} 4548$ while three recruited patients with a different diagnosis (chronic obstructive pulmonary disease, ${ }^{38}$ Parkinson's disease, ${ }^{47}$ advanced heart failure ${ }^{43}$ ). Two studies recruited bereaved family members. ${ }^{44} 53$

\section{Quantitative studies}

\section{Components of interventions}

To examine which types of continuity were implemented within each intervention, we considered the elements within each intervention separately. Each intervention was complex and included multiple components. In total, the interventions included 12 different components, used in a variety of combinations (table 4 ). All interventions included regular contact or follow-up appointments with the same healthcare professional (relational continuity) and the majority included liaison between medical teams (informational continuity) $(86 \%, \mathrm{n}=6)$.

\section{Impact of interventions upon identified outcomes}

Due to the heterogeneous nature of studies it was not possible to conduct a meta-analysis. A narrative summary of the findings of interventional studies, with regard to preferred place of death, hospital admissions and satisfaction with care is provided.
Place of death

Over half of interventions identified explored impact on place of death $\left(n=4,57 \%\right.$ interventional studies). ${ }^{37} 40-42$ Two interventions ${ }^{37}$ reported a positive impact on facilitating preferred place of death while this was difficult to assess in two interventions due to a lack of comparator or limited information being reported. No studies described a negative impact, or a decrease in the number of deaths occurring in the preferred locations.

Preferred place of death was achieved for $91 \%$ of patients (92 of 101 participants for whom this was known) receiving care from the 'Hospice Assist at Home' intervention. ${ }^{42}$ Patients receiving care coordination from a GP registrar were more likely to die at home than control participants (OR 0.41 (95\% CI 0.20 to 0.86 ); $\mathrm{p}=0.02$ ) in van de Mortel et al's intervention.

O'Connor et al report that preferred place of death was achieved for $59 \%$ of participants that died during the study period (20/34 participants). In the absence of a control group, the authors compare this to figures from the wider Australian population which state that $14 \%$ of those that wish to die at home, do so. Morris et al did not report preference for place of death. ${ }^{41}$

\section{Hospital admissions}

Six studies explored the impact of intervention on hospital admission rates. ${ }^{36-41}$ The majority ${ }^{37-40} \quad(n=4)$ described a reduction in avoidable hospital admissions for people enrolled in interventions. In two studies a lack of comparison information makes this difficult to assess, although no interventions describe increases in hospital admissions.

The four studies reporting a reduction in hospital admissions used the following types of intervention: care coordination by a GP registrar, ${ }^{37}$ a nurse practitioner, ${ }^{40}$ a specialist nurse ${ }^{38}$ and an intervention to improve care transitions including postsurgical follow-up calls and mandatory early follow-up appointments with oncology teams. ${ }^{39}$ A number of limitations were observed including differences between the control and intervention groups at baseline, ${ }^{37}$ small sample sizes ${ }^{38}$ and lack of preintervention data. ${ }^{40}$

While Morris et al report that $90 \%$ ( 70 out of 78 ) of care home residents desiring a palliative course, enrolled in a model of palliative care consultation were never hospitalised, the lack of comparison data make conclusions difficult. Seven participants were hospitalised over the course of the intervention, despite orders for no hospitalisation, although this represents less than $10 \%$ of the sample.

Edwards et al relied on participant-reported healthcare utilisation to assess impact on hospital admissions. While participants were enrolled in a seamless care programme, other sources of medical care were still sought. Data from the control condition were not reported.

\section{Patient satisfaction with care}

No interventional studies measured the impact of the intervention on patient or carer satisfaction with care. 


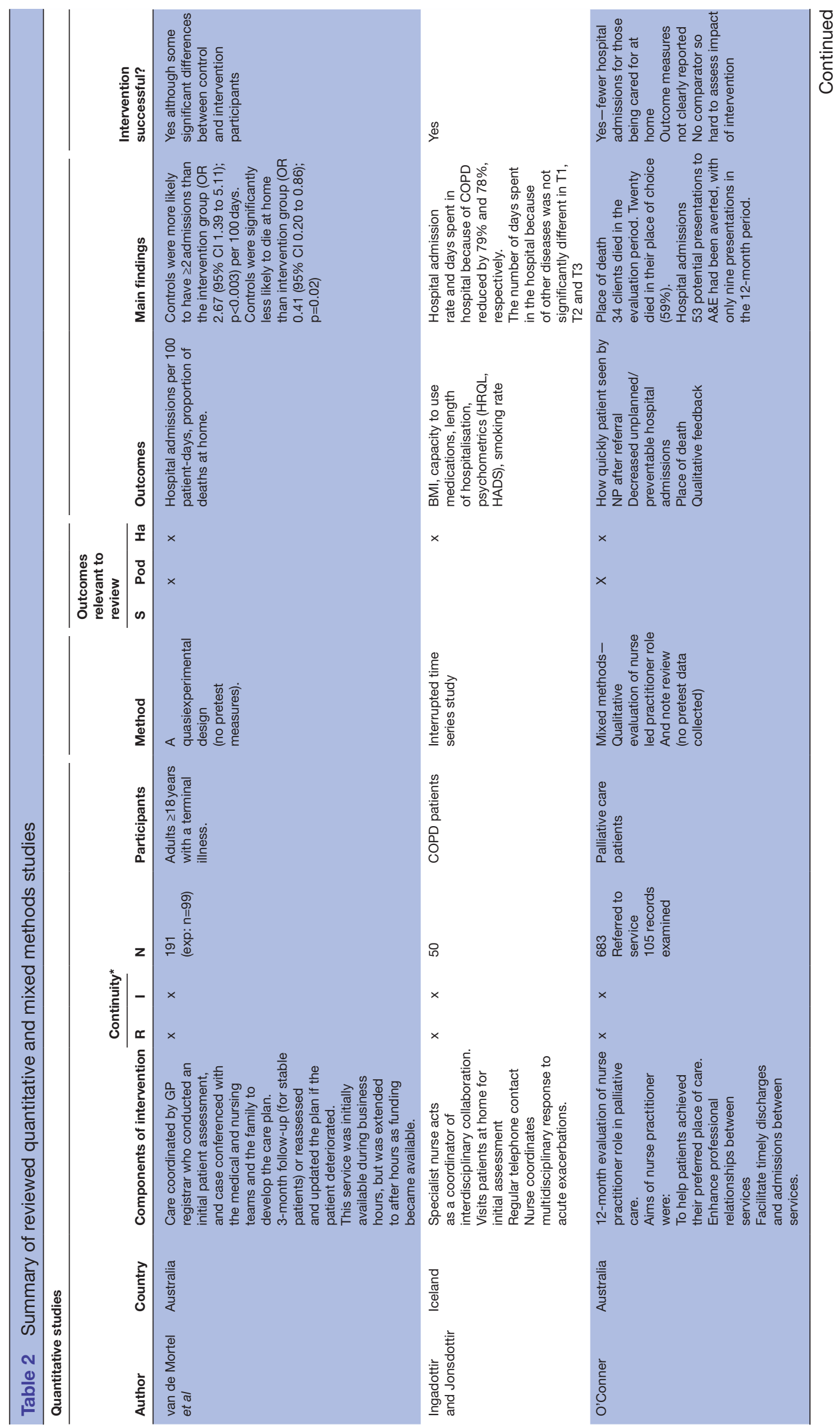

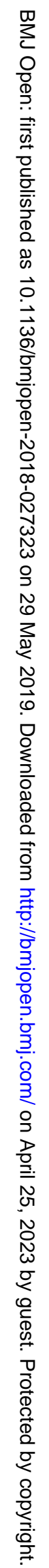




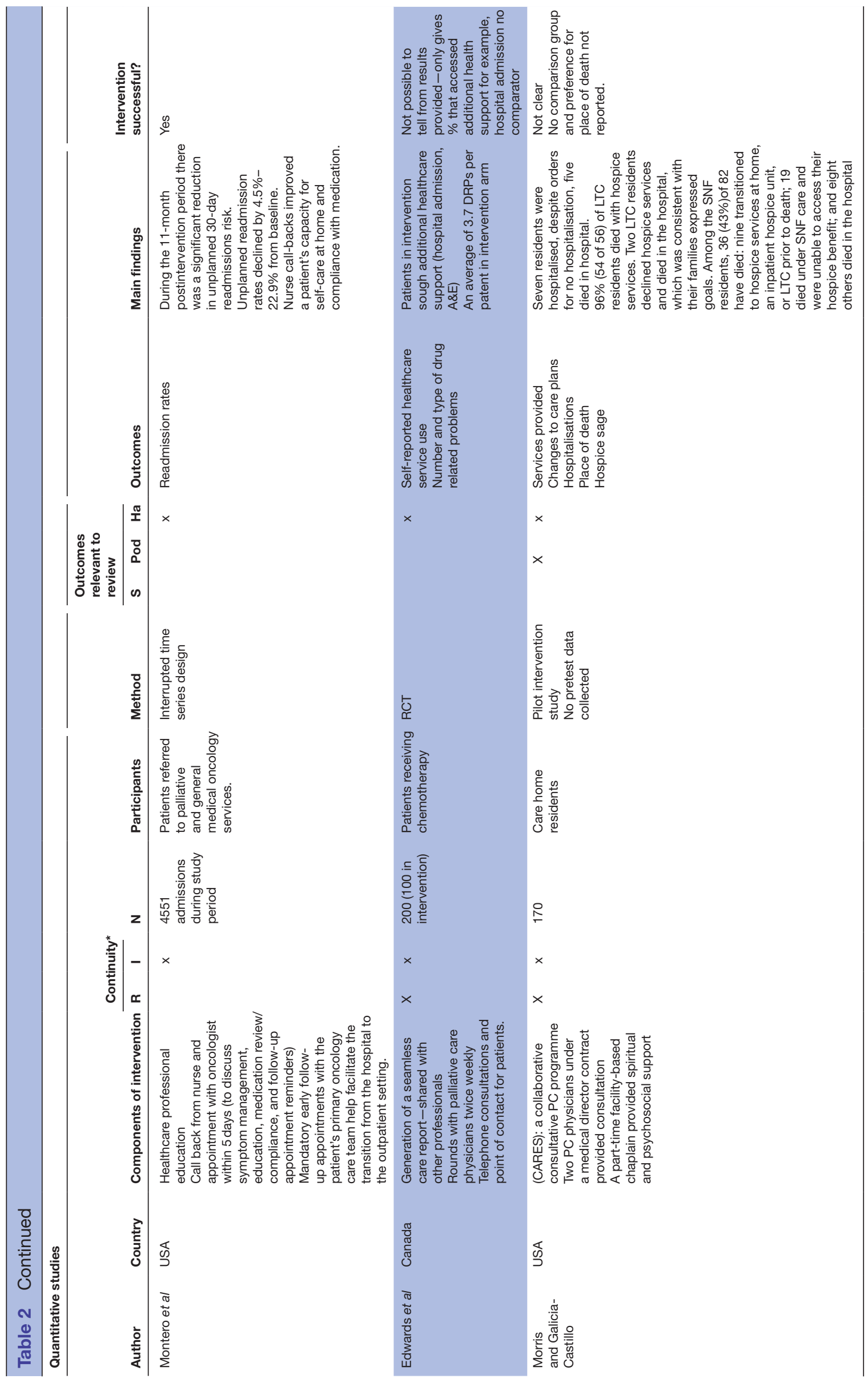

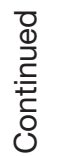




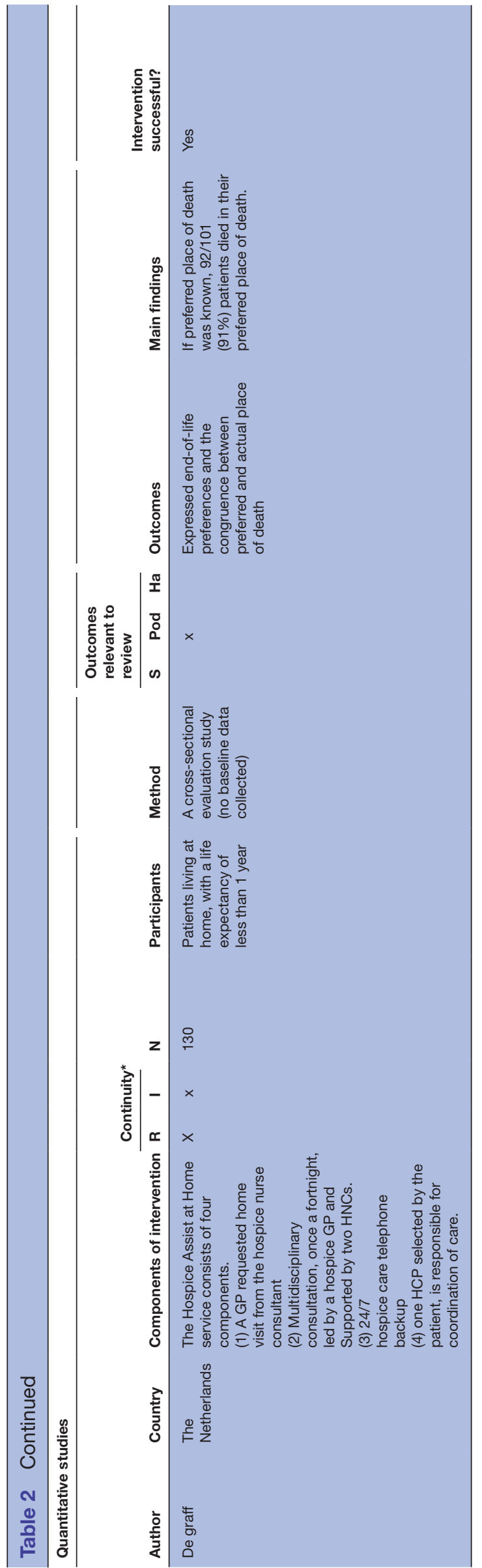

\section{Qualitative synthesis-patient experience of continuity}

The impact of experiencing, or not experiencing continuity of care was explored via qualitative studies. The views of both patients and their informal carers are represented. Barriers to achieving continuity of care and continuity facilitators were identified. An overview of these barriers and facilitators are presented in table 5 .

\section{Barriers to continuity}

We were never quite sure who was in charge of all this business, so who was in charge of it all? (Patient) ${ }^{44}$

The fragmented nature of services and the number of professionals involved made it difficult for some patients to navigate services, ${ }^{44} 475053$ decipher who was responsible for which aspects of their care ${ }^{4350}$ and ultimately access support. This appeared to be amplified outside normal working hours. ${ }^{4450}$ In addition, a lack of information sharing, both between services, and between services and patients left families feeling frustrated and unsupported. ${ }^{445} 45$ Disbelief about the lack of access that professionals had to their medical records was expressed in several studies. ${ }^{44} 4548505253$

\section{Impact of low continuity on patients and families Impact on care \\ Difficulties and delays in accessing support}

You're trying to navigate it and you're dealing with so many agencies and you don't know which way to go sometimes. They're very good in that particular sphere in that they'll try and help you as much as possible, but it's so-I didn't realize it was so complicated to die, I didn't, honestly. I thought it'd be a fairly simple job, but it's not, it's not. (P2, 61-year-old to 70-year-old male patient) ${ }^{49}$

Participants described a significant impact on their experiences as a result of the lack of informational and relational continuity. Patients and carers described difficulty in navigating the numerous services and multiple people involved in their care. ${ }^{44} 475053$ Many described uncertainty about how ${ }^{4350}$ and when ${ }^{4550}$ to access support. A lack of confidence in out of hour's services was also described. ${ }^{44} 4750$

If anything goes wrong during the night, weekends, they were dreadful times because at weekends the NHS more or less closes down, and you can go and sit in A\&E, somebody'll come and see you after about half an hour and take some details, but then it's about 4 hours wait then, and if you're sat there in pain it's a hell of a long tim. (Patient) ${ }^{44}$

As a result of such concerns and experiences, delays in seeking support out of hours were commonly described. Delays were connected to the lack of confidence in services (due to a lack of relational and informational continuity) as well as uncertainties around the legitimacy of their need ${ }^{450}$ and concerns about putting additional strain on the health service, which they perceived as stretched. ${ }^{450}$ Thus patients described waiting until they 
Table 3 Summary of reviewed qualitative studies

\begin{tabular}{llllll} 
Author & Country & $\mathbf{n}$ & Participants & Methodology & Main findings \\
\hline Leydon et al & UK & 32 & $\begin{array}{l}\text { Patients } \\
\text { receiving } \\
\text { palliative care }\end{array}$ & $\begin{array}{l}\text { Longitudinal prospective } \\
\text { qualitative study using } \\
\text { semistructured interviews } \\
\text { and telephone interviews } \\
\text { over 6months - qualitative } \\
\text { descriptive approach to analysis }\end{array}$ & $\begin{array}{l}\text { Interpersonal or relationship continuity and } \\
\text { management continuity are vital to the process } \\
\text { of optimising the patient experience of out of }\end{array}$ \\
& & &
\end{tabular}

Seamark et al UK 54 Bereaved family Semistructured interviews,
members thematic analysis

Continuity of care that divided into personal, organisational and informational continuity. Large numbers and changes in care staff diluted personal continuity and failure of the GPs to visit was viewed negatively.

Family carers had low expectations of informational continuity, finding information often did not transfer between secondary and primary care and other care agencies. Organisational continuity when present provided comfort and reassurance, and a sense of control.

\begin{tabular}{|c|c|c|c|c|}
\hline Payne et al & UK & $\begin{array}{l}\text { Patients }(n=34) \text {, } \\
\text { carers }(n=13) \\
\text { and health } \\
\text { professional } \\
(n=23)\end{array}$ & $\begin{array}{l}\text { Patients, carers } \\
\text { and health care } \\
\text { professionals } \\
\text { (HCPs) }\end{array}$ & $\begin{array}{l}\text { Serial interviews with patients } \\
\text { and family members (either } \\
\text { together or apart) } \\
\text { Focus groups with healthcare } \\
\text { professionals (not included in } \\
\text { analysis) } \\
\text { Thematic analysis and cross } \\
\text { case synthesis }\end{array}$ \\
\hline Richards et al & UK & 28 & $\begin{array}{l}\text { Patients with } \\
\text { advanced } \\
\text { cancer and } \\
\text { caregivers }\end{array}$ & $\begin{array}{l}\text { Interviews with patients and } \\
\text { caregivers. } \\
\text { Thematic analysis }\end{array}$ \\
\hline
\end{tabular}

While some care fell short of expectations, all patients reported high levels of satisfaction and valued continuity of care and efficient information sharing.

All hospices supported and supplemented local providers, with three hospices also supplanting local provision by providing in-patient facilities.

Participants reported a lack of relational and informational continuity of care. Consulting with an unfamiliar clinician out-of-hours raised doubts in some participants' minds about the quality of care.

While the themes suggest the delivery of out-ofhours care as a whole was not always perfect, around-the-clock access to professional sources of support and reassurance was highly valued.

However, the transfer of information to outof-hours providers remains a key challenge; participants did not understand why outof-hours providers could not access more information on their medical histories given the level of computerisation within the National Health Service. The findings highlight the need to improve continuity between in-hours and out-of-hours services for patients with complex needs.

\begin{tabular}{|c|c|c|c|c|c|}
\hline Klarare et al & Sweden & 13 & $\begin{array}{l}\text { six patients and } \\
\text { seven family } \\
\text { members }\end{array}$ & $\begin{array}{l}\text { Interviews } \\
\text { Thematic analysis }\end{array}$ & $\begin{array}{l}\text { Two themes were constructed through thematic } \\
\text { analysis: } \\
\text { (1) security and (2) continuity of care }\end{array}$ \\
\hline Bailey et al & UK & 109 & $\begin{array}{l}39 \text { patients ( } 15 \\
\text { with COPD and } \\
24 \text { with lung } \\
\text { cancer), } \\
20 \text { informal } \\
\text { carers } \\
50 \text { healthcare } \\
\text { professionals, }\end{array}$ & $\begin{array}{l}\text { Semistructured interviews, } \\
\text { after admission and following } \\
\text { discharge } \\
\text { Thematic analysis }\end{array}$ & $\begin{array}{l}\text { Patients were satisfied with their 'emergency' } \\
\text { care but not the care they received once their } \\
\text { initial symptoms had been stabilised. The } \\
\text { poorer quality care they experienced was } \\
\text { characterised by a lack of attention to their } \\
\text { fundamental needs, lack of involvement of the } \\
\text { family, poor communication about care plans } \\
\text { and a lack of continuity between primary and } \\
\text { secondary care. }\end{array}$ \\
\hline Mclaughlin et al & UK & 26 & $\begin{array}{l}\text { Family } \\
\text { caregivers of } \\
\text { people with } \\
\text { Parkinson's } \\
\text { disease }\end{array}$ & $\begin{array}{l}\text { Semistructured interviews } \\
\text { 'a framework was used to guide } \\
\text { analysis' }\end{array}$ & $\begin{array}{l}\text { Lack of continuity between services means } \\
\text { that carers were unaware of support until } \\
\text { they reached a crisis and described difficulty } \\
\text { accessing information. } \\
\text { Carers called for a more integration between } \\
\text { primary, secondary and tertiary care. } \\
\text { Patients sought advice from neurologists over } \\
\text { GPs who were not seen as having high levels } \\
\text { of knowledge about PD. Palliative care was not } \\
\text { accessed by any patients. }\end{array}$ \\
\hline
\end{tabular}


Table 3 Continued

\begin{tabular}{lllll}
\hline Author & Country & $\mathbf{n}$ & Participants & Methodology \\
\hline Neergaard et al & Denmark & 14 & $\begin{array}{l}\text { Bereaved care } \\
\text { givers (cancer } \\
\text { patients) }\end{array}$ & $\begin{array}{l}\text { Focus groups qualitative } \\
\text { description approach }\end{array}$
\end{tabular}

Main findings

patients)

Relatives experience insufficient palliative care, mainly due to organisational and cultural problems among professionals. There is a lack of shared care.

Mixed experiences regarding relationships with GPs, some good, some bad.

Lack of care coordinator identified as barrier to shared care and high quality care.

\begin{tabular}{|c|c|c|c|c|c|}
\hline Browne et al & UK & $\begin{array}{l}115 \\
\text { patients }(n=30), \\
\text { carers }(n=20), \\
\text { professionals } \\
(n=65) .\end{array}$ & $\begin{array}{l}\text { Advanced heart } \\
\text { failure patients } \\
(n=30) \text {, carers } \\
(n=20) \text {, and } \\
\text { professionals } \\
(n=65) .\end{array}$ & $\begin{array}{l}\text { Semistructured interviews } \\
\text { (patients and carers) and focus } \\
\text { groups (HCPs) content analysis }\end{array}$ & $\begin{array}{l}\text { Four key problems: } \\
1 \text { Knowledge and understanding deficits. } \\
2 \text { Difficulties navigating and accessing health } \\
\text { and social care support. } \\
3 \text { General challenges and barriers to optimal } \\
\text { care. } \\
4 \text { Problems relating to emergency care. } \\
\text { Fragmented care with lack of coordination and } \\
\text { poor communication makes life difficult }\end{array}$ \\
\hline
\end{tabular}

COPD, Chronic Obstructive Pulmonary Disease.

could speak to a professional who was familiar with them and their needs before seeking help. This resulted in many patients enduring unpleasant symptoms while they waited to contact their regular care providers, which was also disturbing for carers. ${ }^{44} 454850$

.... Um ... so, no, in the end I decided there wasn't anybody, really, who could help me, (IV: Mmm), so I didn't call anybody, I just sent my nurse a text and just hoped I'd survive the night. And I did [gentle laughter from P]. (Patient) ${ }^{50}$

\section{Care plan is poorly communicated}

The lack of consistent communication, and difficulty in accessing support meant that often, it was hard for patients to build up a clear picture of their current status. ${ }^{4352}$ This ambiguity left patients feeling unsupported and unclear about what the future held for them.
We're waiting to hear from them, the [regional hospital], they said a week or two... it's actually three weeks [now]... I know they say no news is probably good news, but waiting is the worst part. You just want to know how long you've got. (Patient) ${ }^{52}$

The inability of all services to access a patient's medical records complicated care and was a source of much frustration and led to periods of unnecessary stress and discomfort. This again, was particularly pressing outside of normal working hours and necessitated much repetition of information and contributed to a reluctance to access out of hours support. ${ }^{4445} 4850$

Well by the time you phone one person and you try to explain to them that you've got a growth inside you and it's bothering you and you're in a lot of pain and stuff, then they have to go and get somebody else 
Table 4 Components of eligible interventions

\begin{tabular}{|c|c|c|c|c|c|c|c|c|c|}
\hline & $\begin{array}{l}\text { Type of } \\
\text { continuity }\end{array}$ & De Graff & $\begin{array}{l}\text { Edwards } \\
\text { et al }\end{array}$ & $\begin{array}{l}\text { Ingadottir and } \\
\text { Jonsdottir }\end{array}$ & $\begin{array}{l}\text { Montero } \\
\text { et al }\end{array}$ & $\begin{array}{l}\text { Morris and } \\
\text { Galicia- } \\
\text { Castillo }\end{array}$ & $\begin{array}{l}\text { van de Mortel } \\
\text { et al }\end{array}$ & O'Conner & $\begin{array}{l}\text { Number of } \\
\text { studies }\end{array}$ \\
\hline Care coordinator identified & R\&l & $x$ & & $x$ & & & $x$ & $x$ & 4 \\
\hline $\begin{array}{l}\text { Contact with same professionals } \\
\text { out of hours }\end{array}$ & R\&l & & & & & & $x$ & & 1 \\
\hline $\begin{array}{l}\text { Regular contact/follow-up up } \\
\text { appointments with the same } \\
\text { healthcare professional }\end{array}$ & R\&l & $x$ & $x$ & $x$ & $x$ & $\mathrm{x}$ & $\mathrm{x}$ & $x$ & 7 \\
\hline $\begin{array}{l}\text { Patient selects which professional } \\
\text { acts as their coordinator }\end{array}$ & $\mathrm{R}$ & $x$ & & & & & & & 2 \\
\hline $\begin{array}{l}\text { Initial medication history interview } \\
\text { and medical reconciliation } \\
\text { conducted }\end{array}$ & I & & $x$ & & & & & & 2 \\
\hline $\begin{array}{l}\text { Liaison between medical teams } \\
\text { (MDTs, case conferences) }\end{array}$ & 1 & $x$ & $x$ & $x$ & & $x$ & $x$ & $x$ & 6 \\
\hline $\begin{array}{l}\text { Education for healthcare } \\
\text { professionals to promote buy in } \\
\text { to intervention/promote continuity }\end{array}$ & I & $x$ & & & $x$ & $\mathrm{x}$ & & & 3 \\
\hline $\begin{array}{l}\text { Creation of a (new) care Plan/ } \\
\text { database/report }\end{array}$ & 1 & $x$ & $x$ & & & $x$ & $x$ & $x$ & 5 \\
\hline
\end{tabular}

MDTs, multidisciplinary team meetings; I, informational continuity; $R$, relational continuity.

to phone you back and you have to wait a long time ... eventually they do phone you back ... and then you're in absolute agony on the phone. (Patient) ${ }^{48}$

This was compounded by a lack of consistency in symptom management, with different professionals suggesting different approaches. ${ }^{43} 4752$ This was sometimes described as a result of delayed or irregular medical reviews with specialists, or the lack of coordinated approach to care. This had a negative impact on both patients and carers. ${ }^{51} 52$
They took a lot of tablets off me [in the hospital], and my doctor [GP] went mad, because they shouldn't have done... I'm back on all my old medication now... they shouldn't have changed it. (Patient) ${ }^{52}$

In addition, in the absence of a coordinated approach meant that the care patients received was often not streamlined with repetition and multiple appointments within the same location, within the same week often taking place. ${ }^{43} 46$

Table 5 The barriers and facilitators to continuity in the provision of palliative care, and the impact of continuity on patient and carer experience

\begin{tabular}{ll} 
Barriers and facilitators of continuity & Impact on patient \\
\hline Barriers to continuity & Impact of poor continuity on patients and carers \\
Structure of systems & Impact on care \\
- Fragmented services. & - Difficulties and delays in accessing support. \\
- Multiple professionals involved. & - Care plan is not clearly communicated to patients. \\
Lack of information sharing & Impact on patient and carers \\
- Between primary and secondary services. & - Emotional impact. \\
- limited access to medical records. & - Additional burdens. \\
Continuity facilitators & Benefits of continuity for patients and carers \\
- One point of contact-care coordinator & Patient feels 'known' \\
Multidisciplinary working. & Patient is confident in care.
\end{tabular}


She says he is down at the same department three times in a week and he could be done in one day. Each of them that, the Sister, the Nurse and the anticoagulant clinic. She says it's the same building and yet he has got to go three times daily, he's got to go three times a week, different days. (Carer) ${ }^{43}$

Further consequences of this lack of continuity were that some families described being unaware of sources of support (for example additional financial support or additional out of hours support), which could have been beneficial for them. ${ }^{4450}$ Patients felt that some professionals presumed that someone else had already provided them with this information, a lack of continuity meant that gaps in information provision were sometimes left unfilled. ${ }^{4750}$

I was surprised in retrospect that I hadn't been told that [about out-of-hours service]... perhaps they thought I knew... [Would have been less worried over the years if I'd known]. (Patient) ${ }^{50}$

The lack of informational and relational consistency experienced by patients and families negatively impacted their experiences of care, with patients enduring periods of great discomfort in order to wait until they could seek help from a professional that was familiar with their needs, and with whom they felt confident and supported.

\section{Impact on patient and carer experience} Additional burdens

\section{Taking on the role of coordinator}

Due to a lack of informational continuity between services, patients and carers took on additional administrative burdens or duties to secure a coherent approach to care management. ${ }^{44} 475153$ Patients and carers described having to take on the role of 'coordinator', as services did not seem to be effectively sharing information with each other. This was experienced as stressful and time consuming.

It was up to me to contact her [the hospice nurse], and this is what people say, if you need any help ring, but it's an extra thing to do, to organise your own kind of help is an extra thing to do, and in the 24 hours you don't have much time or energy for extra things. (Patient) ${ }^{44}$

Some carers described an 'unspoken pressure' from healthcare professionals to become 'semi-professionals' ${ }^{53}$ This was also a role that many people did not want, patients were often too tired and carers preferred to concentrate on spending quality time with loved ones. ${ }^{45}$

I mean our own GP obviously knows Dad's case inside out, but there must be a way where the [out-of-hours] doctor can access at least a recapped version of what's wrong with him you would think he had to tap into his computer and access everything but, you know, he went solely on what I told him when we went in. So that to me was strange. (Carer) ${ }^{45}$

\section{Feeling vulnerable or out of control}

In addition to the more practical impacts of low continuity (both relational and informational) significant emotional impacts for patients and families were reported. ${ }^{450}$ Many carers reported feeling vulnerable or out of control when they could not access advice or support from a professional who was familiar with their history and needs.

And I remember thinking, I'm vulnerable, my wife is in pain and we want a service and, and I have to ring up this person-'The doctor will contact you'! What, tonight? Tomorrow? (Carer) ${ }^{45}$

For patients, a lack of relational continuity meant that they could feel alone and unsupported.

All I wanted was a voice to recognize me, um, or, or a voice to recognize what I was doing and say, there, there, [name], that's OK, I'll speak to you tomorrow, I'm aware of what's wrong with you, um, and that's fine. And really, the only voice who could do that would be [name], my, my nurse, um ... but obviously she switches her phone off, I think she [finishes her shift] at 5 o'clock... (Patient) ${ }^{50}$

\section{Continuity facilitators}

In response to the fragmented nature of systems, patients and carers agreed that it would be beneficial to have one point of contact for their queries and concerns. ${ }^{44} 485153$ Some participants suggested this role could be occupied by a GP, ${ }^{48} 53$ while others felt that the qualifications of the individual were less important than their ability to be a consistent source of advice, signposting or support. ${ }^{49}$ Furthermore, to truly promote continuity the need for multidisciplinary teams was highlighted.

\section{Benefits of continuity for patients and carers}

\section{Feeling known}

One of the most positive aspects of continuity from the perspectives of participants was that of 'feeling known', which was represented in a number of ways. 'Feeling known' was related to recognition of who the patient was as a person, being listened to and having the professional demonstrate their ability to use their knowledge of the individual to recognise and act on their suffering in a person centred manner. ${ }^{44} 46{ }^{48-50}$ Where this level of relational continuity was achieved, it was highly valued.

Yes, there was a nurse, a man, who came last week and took some blood. And I think he has been here once or maybe twice before. So, he asks me, how is your eating? Because I'd had problems last autumn, I lost a lot of weight... I think it is fantastic that he remembers... They care about the little things, ask how I've been over the holidays, what I've done, and so on. (Patient) ${ }^{46}$ 
Another aspect of 'feeling known' that was appreciated by carers in particular was the ability to notice small but potentially significant changes in a patient that could only be achieved through consistent interactions. ${ }^{44} 4649$ In addition, for patients being cared for at home, families felt more comfortable when they had developed a relationship with healthcare professionals.

But it would be wonderful if one nurse could concentrate on a case because you would have that continuity and they would notice changes and things and it would help them and probably help the family in that it isn't a different person every night and you're having to explain where the coffee is and what to do, but I know it isn't practical because they have to have time off. But if it were one person, or even two, because we did have several different nurses. (Carer) ${ }^{44}$

\section{Feeling confident in care}

Continuity in all of its forms, bolstered a sense of confidence in both care providers and the care plans developed for them. ${ }^{46} 495053$ Patients described feeling confident that their team could support them.

There's nothing worse than feeling that you are on your own and there's no support and like it's the unknown. When you know that you can pick up the phone and at the other end are experienced professionals and they are like tuned in and that in a matter of minutes you can have assistance. That makes all the difference. (Patient) ${ }^{45}$

The ability to contact a team that could respond quickly and appropriately was greatly appreciated by patients and carers and went some way to alleviating some of the anxiety associated with supporting a loved one with palliative care needs.

...it happened in a few hours. He got a high temperature... but they came straight away and stood here with the doctor on the phone, and it felt like 'Yes, they've got it covered.' That felt like WOW! ...They came for this and supported us, and that was great since... It almost caused anxiety before [enrollment in SPHC] to have to call the healthcare center... No one [there] has the complete picture, and no one knows us... No continuity. (Carer) ${ }^{46}$

\section{DISCUSSION}

\section{Summary of findings}

This mixed methods rapid review explored the impact of continuity for patients receiving palliative care. The limited quantitative evidence reviewed indicated that improving continuity of care may be related to reduced hospital admissions and achieving preferred location of death, although this review does not provide conclusive evidence of this.
Poor continuity was described as related to delays and difficulties in accessing care and increasing the burdens experienced by patients and carers. Patients were often left feeling vulnerable or unsupported without a clear understanding of their care plan and how to access support. In contrast, when patients experienced good continuity of care they felt confident, known and supported by care providers.

\section{Comparison to other literature and the wider context}

Many of the facilitators for continuity for palliative patients identified in this review (having one point of contact, and strong multidisciplinary working and information sharing), and the perceived benefits of continuity (accumulated knowledge) were identified in a review of the impact of continuity for patients with a range of conditions. ${ }^{21}$ Waibel et al note that continuity could be enhanced when patients take an active approach to the management of their own care. In the current review, in palliative care, participants and carers experienced the need to adopt the role of coordinator as burdensome and unwelcome. This may reflect both similarities and differences in how to promote continuity for patients with different conditions and at different stages of illness.

The impact of poor informational continuity for palliative patients was highlighted in this review. Retrospective studies highlight potential strategies for promoting continuity for this group, including electronic information sharing. Electronic palliative care coordination (EPaCC) systems $^{54}$ have been suggested as useful in promoting information continuity for palliative care patients, although further work is needed to develop and test such strategies.

This review also highlights the importance of relational continuity for palliative care patients. Informational continuity is clearly important, but in isolation may be insufficient to achieve optimal patient outcomes or experiences. The importance of 'feeling known' by healthcare professionals was clear in this review, both for the emotional and physical well-being of patients (in terms of delaying access to out of hours services). These benefits have been described in previous research within palliative populations. ${ }^{55}$

Despite evidence of the beneficial impact of continuity of care on both patient outcomes and experiences, continuity is not 'built in' to interventions in the same way as other aspects of healthcare delivery. ${ }^{56}$ The number of retrospective studies in this area suggests that continuity is currently considered more of an outcome than an integral part of the healthcare process. This needs to be addressed. While there are undoubtedly methodological challenges in exploring the impact of interventions designed to promote continuity, this is an area in which future research is needed. It was also interesting to note that no quantitative studies included measures of patient satisfaction with care. Given the themes identified in the qualitative data, highlighting the positive impact that continuity had on their experiences of care and support, 
this is perhaps something to be considered in future studies.

Continuity of care is difficult to deliver, and can be hard to measure, but is vitally important to patients. Relational continuity provides the context on which to build individualised care plans for patients, that in turn, requires informational and managerial continuity between services to be effective. Improving continuity in palliative care may not remove every negative experience for palliative care patients and their families. However, the contrasts in reports of patients who had, and had not, perceived continuity in their care in this review demonstrate the beneficial effects that continuity can have in terms of feeling safe, known and supported. While continuity may not be the panacea for all the challenges in providing high quality palliative care, we believe that good continuity, in a range of forms, can go a long way to improving a difficult time in a family or a person's life. We acknowledge that where continuity is more integrated into care, or where elements of interventions are not identified as continuity facilitators, they may not have been included in this review.

\section{Limitations}

There are a number of limitations to this review that warrant consideration. This rapid review was completed within 12 weeks and only research published within the last 10 years was included, grey literature and the views of healthcare professionals were not included.

Half of included studies were conducted in the UK. We acknowledge that patient experiences are shaped by the healthcare services and structures of the country in which they are receiving care, however aspects of the experience of both good and poor continuity may transcend national borders.

Defining which interventions should be considered eligible for inclusion in this review was a challenge given the various definitions and approaches to continuity found in the literature. Consensus over whether an article was eligible for inclusion was assessed through consulting the full text articles, referring back to the definitions of continuity outlined in Haggerty et $a l$ s review ${ }^{2}$ and discussion among the research team.

\section{Implications for future research and practice}

The development of future interventions to improve care for palliative patients should consider how strategies for promoting both information and relational continuity can be embedded within interventions, and subsequently healthcare, alongside robust methods to measure the extent and impact of continuity achieved.

\section{CONCLUSIONS}

The impact of poor continuity and the potential benefits of improved continuity highlighted in this review add additional evidence to the body of literature calling for increased efforts to promote both informational and relational continuity for palliative care patients. Methods for enhancing, and recording continuity should be considered in the design and development of future healthcare interventions, across the lifespan.

Contributors BFH, BN and SB conceptualised the study. BFH designed the search strategy. BFH ran the search strategy. BFH screened the articles, extracted data, analysed the results and drafted the manuscript. BN reviewed eligible articles. BFH, BN, SB and PS critically reviewed several drafts of the manuscript and approved the final draft.

Funding BFH, SB and BN's role were supported by Marie Curie. PS's role was supported by the Marie Curie Chair's grant. PS is supported by the UCLH NIHR Biomedical Research Centre.

Competing interests None declared.

Patient consent for publication Not required.

Provenance and peer review Not commissioned; externally peer reviewed.

Data sharing statement № additional data are available for this manuscript.

Open access This is an open access article distributed in accordance with the Creative Commons Attribution Non Commercial (CC BY-NC 4.0) license, which permits others to distribute, remix, adapt, build upon this work non-commercially, and license their derivative works on different terms, provided the original work is properly cited, appropriate credit is given, any changes made indicated, and the use is non-commercial. See: http://creativecommons.org/licenses/by-nc/4.0/.

\section{REFERENCES}

1. Freeman G, Hughes J. Continuity of care and the patient experience. An Inquiry into the Quality of General Practice in England: The Kings Fund, 2010.

2. Haggerty JL, Reid RJ, Freeman GK, et al. Continuity of care: a multidisciplinary review. BMJ 2003;327:1219-21.

3. Mainous AG, Baker R, Love MM, et al. Continuity of care and trust in one's physician: evidence from primary care in the United States and the United Kingdom. Fam Med 2001;33:22-7.

4. Pandhi N, Saultz JW. Patients' perceptions of interpersonal continuity of care. J Am Board Fam Med 2006;19:390-7.

5. BMA. National Survey of GPs. The Future of General Practice. 2015. British Medical Association.

6. Hjortdahl P, Borchgrevink CF. Continuity of care: influence of general practitioners' knowledge about their patients on use of resources in consultations. BMJ 1991;303:1181-4.

7. Broom DH. Familiarity breeds neglect? Unanticipated benefits of discontinuous primary care. Fam Pract 2003;20:503-7.

8. Brousseau DC, Meurer JR, Isenberg ML, et al. Association between infant continuity of care and pediatric emergency department utilization. Pediatrics 2004;113:738-41.

9. Nyweide DJ, Bynum JPW. Relationship Between Continuity of Ambulatory Care and Risk of Emergency Department Episodes Among Older Adults. Ann Emerg Med 2017;69.

10. Fan VS, Burman M, McDonell MB, et al. Continuity of care and other determinants of patient satisfaction with primary care. J Gen Intern Med 2005;20:20.

11. Menec VH, Sirski M, Attawar D, et al. Does continuity of care with a family physician reduce hospitalizations among older adults? J Health Serv Res Policy 2006;11:196-201.

12. Barker I, Steventon A, Deeny SR. Association between continuity of care in general practice and hospital admissions for ambulatory care sensitive conditions: cross sectional study of routinely collected, person level data. BMJ 2017;356:j84.

13. Lustman $A$, Comaneshter D, Vinker S. Interpersonal continuity of care and type two diabetes. Prim Care Diabetes 2016;10:165-70.

14. Pereira Gray DJ, Sidaway-Lee K, White E, et al. Continuity of care with doctors-a matter of life and death? A systematic review of continuity of care and mortality. BMJ Open 2018;8:e021161.

15. NICE. Patient experience in adult NHS services. London, 2012.

16. Physicians ACo. The Patient-Centered Medical Home Neighbor: The Interface of the Patient-Centered Medical Home with Specialty/ Subspecialty Practices. Philadelphia: American College of Physicians, 2010.

17. Hill A, Freeman GK. Promoting Continuity of Care in General Practice: Royal College of Physicians, 2011.

18. Osborn R, Moulds D, Schneider EC, et al. Primary Care Physicians In Ten Countries Report Challenges Caring For Patients With Complex Health Needs. Health Aff 2015;34:2104-12. 
19. Rosen R, Kumpunen S, Curry N. Is bigger better? Lessons for largescale general practice: Nuffield Trust, 2016.

20. Bodenheimer T, Haq C, Lehmann W. Continuity and Access in the Era of Part-Time Practice. Ann Fam Med 2018;16:359-60.

21. Waibel S, Henao D, Aller MB, et al. What do we know about patients perceptions of continuity of care? A meta-synthesis of qualitative studies. Int J Qual Health Care 2012;24:39-48.

22. Murtagh FE, Bausewein C, Verne J, et al. How many people need palliative care? A study developing and comparing methods for population-based estimates. Palliat Med 2014;28:49e58.

23. Gardiner C, Gott M, Ingleton C. Factors supporting good partnership working between generalist and specialist palliative care services: a systematic review. Br J Gen Pract 2012;62:e353-62.

24. Smith R, Best S, Noble B. Identifying palliative and end-of-life care research priorities: a UK approach to consult end users. European Journal of Paliative Care 2015:114-7.

25. Heerdegen ACS, Petersen GS, Jervelund SS. Determinants of patient satisfaction with cancer care delivered by the Danish healthcare system. Cancer 2017;123:2918-26.

26. Kim SL, Tarn DM. Effect of Primary Care Involvement on Endof-Life Care Outcomes: A Systematic Review. J Am Geriatr Soc 2016;64:1968-74.

27. Gómez-Batiste X, Murray SA, Thomas K, et al. Comprehensive and Integrated Palliative Care for People With Advanced Chronic Conditions: An Update From Several European Initiatives and Recommendations for Policy. J Pain Symptom Manage 2017;53:509-17.

28. Gee P, Woodward A, Nelson A. Palliative care evidence review service (PaCERS): a rapid systematic approach to identifying high quality evidence on palliative care. BMJ supportive \& palliative care 2016:6.

29. Candy B, Jackson KC, Jones L, et al. Drug therapy for delirium in terminally ill adult patients. Cochrane Database Syst Rev 2012;11:CD004770.

30. van Walraven $\mathrm{C}$, Oake N, Jennings $\mathrm{A}$, et al. The association between continuity of care and outcomes: a systematic and critical review. $J$ Eval Clin Pract 2010;16:947-56.

31. Hawker S, Payne S, Kerr C, et al. Appraising the evidence: reviewing disparate data systematically. Qual Health Res 2002;12:1284-99.

32. Tong A, Flemming K, Mclnnes $\mathrm{E}$, et al. Enhancing transparency in reporting the synthesis of qualitative research: ENTREQ. BMC Med Res Methodol 2012;12:1-8.

33. Campbell R, Pound P, Pope C, et al. Evaluating meta-ethnography: a synthesis of qualitative research on lay experiences of diabetes and diabetes care. Soc Sci Med 2003;56:671-84

34. Thomas J, Harden A. Methods for the thematic synthesis of qualitative research in systematic reviews. BMC Med Res Methodol 2008;8:45.

35. Hudson BF, Flemming K, Shulman C, et al. Challenges to access and provision of palliative care for people who are homeless: a systematic review of qualitative research. BMC Palliat Care 2016;15:96

36. Edwards SJ, Abbott R, Edwards J, et al. Outcomes assessment of a pharmacist-directed seamless care program in an ambulatory oncology clinic. J Pharm Pract 2014;27:46-52.

37. van de Mortel TF, Marr K, Burmeister E, et al. Reducing avoidable admissions in rural community palliative care: a pilot study of care coordination by General Practice registrars. Aust J Rural Health 2017;25:141-7.

38. Ingadottir TS, Jonsdottir H. Partnership-based nursing practice for people with chronic obstructive pulmonary disease and their families: influences on health-related quality of life and hospital admissions. $J$ Clin Nurs 2010;19:2795-805.

39. Montero AJ, Stevenson J, Guthrie AE, et al. Reducing Unplanned Medical Oncology Readmissions by Improving Outpatient Care
Transitions: A Process Improvement Project at the Cleveland Clinic. J Oncol Pract2016.12.

40. O'Connor M, Palfreyman S, Le B, et al. Establishing a nurse practitioner model to enhance continuity between palliative care settings. Int J Palliat Nurs2016;22:.

41. Morris DA, Galicia-Castillo M. Caring About Residents' Experiences and Symptoms (CARES) Program: A Model of Palliative Care Consultation in the Nursing Home. Am J Hosp Palliat Care 2017:34:466-9.

42. de Graaf E, Zweers D, Valkenburg ACh, et al. Hospice assist at home: does the integration of hospice care in primary healthcare support patients to die in their preferred location - A retrospective cross-sectional evaluation study. Palliat Med 2016;30:580-6.

43. Browne S, Macdonald S, May CR, et al. Patient, carer and professional perspectives on barriers and facilitators to quality care in advanced heart failure. PLoS One 2014;9.

44. Seamark D, Blake S, Brearley SG, et al. Dying at home: a qualitative study of family carers' views of support provided by GPs community staff. Br J Gen Pract 2014;64:e796-e803.

45. Richards SH, Winder R, Seamark C, et al. The experiences and needs of people seeking palliative health care out-of-hours: a qualitative study. Prim Health Care Res Dev 2011;12:165-78.

46. Klarare A, Rasmussen BH, Fossum B, et al. Experiences of security and continuity of care: Patients' and families' narratives about the work of specialized palliative home care teams. Palliat Support Care 2017:15:181-9.

47. McLaughlin D, Hasson F, Kernohan WG, et al. Living and coping with Parkinson's disease: perceptions of informal carers. Palliat Med2011.25.

48. Adam R, Clausen MG, Hall S, et al. Utilising out-of-hours primary care for assistance with cancer pain: a semi-structured interview study of patient and caregiver experiences. $\mathrm{Br} J$ Gen Pract 2015;65:e754-60.

49. Jack BA, Mitchell TK, Cope LC, et al. Supporting older people with cancer and life-limiting conditions dying at home: a qualitative study of patient and family caregiver experiences of Hospice at Home care. J Adv Nurs 2016;72:2162-72.

50. Leydon GM, Shergill NK, Campion-Smith C, et al. Discontinuity of care at end of life: a qualitative exploration of $\mathrm{OOH}$ end of life care. BMJ Support Palliat Care 2013;3:412-21.

51. Payne S, Eastham R, Hughes S, et al. Enhancing integrated palliative care: what models are appropriate? A cross-case analysis. BMC Palliat Care 2017;16:64.

52. Bailey C, Hewison A, Karasouli E, et al. Hospital care following emergency admission: a critical incident case study of the experiences of patients with advanced lung cancer and Chronic Obstructive Pulmonary Disease. J Clin Nurs 2016;25:2168-79.

53. Neergaard MA, Olesen F, Jensen AB, et al. Palliative care for cancer patients in a primary health care setting: Bereaved relatives' experience, a qualitative group interview study. BMC Palliat Care 2008;7:1.

54. Allsop MJ, Kite S, McDermott S, et al. Electronic palliative care coordination systems: Devising and testing a methodology for evaluating documentation. Palliat Med 2017;31.

55. Michiels E, Deschepper R, Van Der Kelen G, et al. The role of general practitioners in continuity of care at the end of life: a qualitative study of terminally ill patients and their next of kin. Palliat Med 2007;21:409-15.

56. Aubin $M$, Giguère $A$, Martin $M$, et al. Interventions to improve continuity of care in the follow-up of patients with cancer. Cochrane Database Syst Rev 2012:CD007672. 